\title{
The impact of incomplete revascularization and angiographic patency on midterm results after off-pump coronary artery bypass grafting
}

\author{
Jota Nakano, MD, ${ }^{\text {a,b }}$ Hitoshi Okabayashi, MD, PhD,${ }^{\mathrm{a}, \mathrm{c}}$ Hisashi Noma, $\mathrm{PhD},{ }^{\mathrm{d}}$ Tosiya Sato, $\mathrm{PhD},{ }^{\mathrm{d}}$ and \\ Ryuzo Sakata, MD, $\mathrm{PhD}^{\mathrm{b}}$
}

\begin{abstract}
Objectives: Higher rates of incomplete revascularization (IR) and reduced patency are possible drawbacks of off-pump coronary artery bypass grafting (OPCAB); both may adversely affect outcome after surgery. This study was conducted to shed light on the relationships among IR, angiographic patency, and midterm results after OPCAB surgery.
\end{abstract}

\begin{abstract}
Methods: A total of 1604 consecutive patients underwent OPCAB during a 6-year period; 1581 patients (95\%) underwent systematic postoperative angiography. Complete follow-up was achieved in $99.5 \%$ (median, 3.2 years; up to 6.5 years). A total of 216 patients had IR (13\%), and 225 had at least 1 graft failure (FitzGibbon $\mathrm{B}$ or $\mathrm{O})$.
\end{abstract}

Results: All the event-free survival rates for all-cause mortality $(P<.001)$, cardiac death $(P=.020)$, and major adverse cardiac and cerebrovascular events $(P<.001)$ were lower in the IR group. By using the Cox proportional hazards model, IR was an independent risk factor for all-cause mortality (hazard ratio [HR], 1.80; 95\% confidence interval [CI], 1.15-2.81). Of those who underwent postoperative angiography, the patients with graft failure experienced reintervention more frequently than those with all grafts patent (HR, 5.49; 95\% CI, 3.43-8.77). Even with excluding patients who had undergone reintervention immediately after angiography, graft failure was still an independent risk factor for reintervention afterwards (HR, 2.41; 95\% CI, 1.30-4.47).

Conclusions: Incomplete revascularization was relevant to higher midterm mortality after OPCAB, whereas the risk of reintervention was higher for patients with occluded grafts. Complete revascularization, coupled with achievement of a higher patency rate, could be expected to improve follow-up outcomes after OPCAB surgery.

(J Thorac Cardiovasc Surg 2014;147:1225-32)

Since the introduction of off-pump coronary artery bypass (OPCAB), many studies have been published comparing OPCAB with conventional coronary artery bypass (CCAB). However, for major outcomes, such as mortality, $\mathrm{OPCAB}$ has not been demonstrated to be superior to $\mathrm{CCAB} .{ }^{1}$ In many randomized controlled trials, ${ }^{2}$ the number of anastomoses was fewer and the rate of complete revascularization $(\mathrm{CR})$ was lower in the OPCAB arm than in the $\mathrm{CCAB}$ arm, except for in a few studies ${ }^{3}$; similar observations were reported in retrospective studies. ${ }^{4} \mathrm{CR}$ has been well recognized as a main goal of CCAB. ${ }^{5,6}$ Indeed, investigations

\footnotetext{
From the Department of Cardiovascular Surgery, ${ }^{a}$ Kokura Memorial Hospital, Fukuoka; the Department of Cardiovascular Surgery, ${ }^{\mathrm{b}}$ Kyoto University Graduate School of Medicine, Kyoto; the Department of Cardiovascular Surgery, ${ }^{c}$ Iwate Medical University, Memorial Heart Center, Iwate; and the Department of Biostatistics, ${ }^{\mathrm{d}}$ Kyoto University School of Public Health, Kyoto, Japan.

Disclosures: Authors have nothing to disclose with regard to commercial support.

Received for publication June 12, 2012; revisions received Dec 1, 2012; accepted for publication March 15, 2013; available ahead of print April 15, 2013.

Address for reprints: Jota Nakano, MD, Kyoto University Graduate School of Medicine, 54 Kawahara-cho, Shogoin, Sakyo-ku, Kyoto 606-8507, Japan (E-mail: jotanakano@gmail.com).

$0022-5223 / \$ 36.00$

Copyright (C) 2014 by The American Association for Thoracic Surgery

http://dx.doi.org/10.1016/j.jtcvs.2013.03.026
}

have demonstrated that incomplete revascularization (IR) is one of the predictors of long-term mortality, even in OPCAB patients. ${ }^{7,8}$

Patency rate is another issue with OPCAB. A recently published, large-scale, randomized study ${ }^{2}$ reported a lower patency rate in the OPCAB arm than in the on-pump arm on 12 -month angiograms. This is partly because OPCAB is a more technically demanding procedure than $\mathrm{CCAB}$. In fact, bypass grafting without extracorporeal circulation carries the risk of graft failure.

Lopes et $\mathrm{al}^{9}$ have recently demonstrated that vein graft failure 1 year after coronary artery bypass surgery is associated with an increased risk of death, myocardial infarction (MI), or revascularization at 4 years after the angiogram. This association is driven mostly by revascularization. Retrospective studies have also reported that patients undergoing $\mathrm{OPCAB}$ experienced reintervention more frequently at follow-up than those undergoing $\mathrm{CCAB},{ }^{10,11}$ and this may be owing to both IR and reduced patency in OPCAB. However, the relative contribution of the 2 possible causes has not yet been determined. ${ }^{10,12,13}$ Therefore, this study was conducted to shed light on the associations among IR, systematic angiographic evaluation, and midterm results after OPCAB surgery. 


\begin{tabular}{|c|c|}
\hline \multicolumn{2}{|c|}{ Abbreviations and Acronyms } \\
\hline BITA & $=$ bilateral internal thoracic artery \\
\hline BSA & $=$ body surface area \\
\hline $\mathrm{CCAB}$ & $\begin{aligned}= & \text { conventional coronary artery } \\
& \text { bypass }\end{aligned}$ \\
\hline COPD & $\begin{array}{l}=\text { chronic obstructive pulmonary } \\
\text { disease }\end{array}$ \\
\hline $\mathrm{CI}$ & $=$ confidence interval \\
\hline $\mathrm{CR}$ & $=$ complete revascularization \\
\hline $\mathrm{CRF}$ & $=$ chronic renal failure \\
\hline $\mathrm{CT}$ & $=$ computed tomography \\
\hline \multicolumn{2}{|c|}{$\begin{aligned} \text { EuroSCORE }= & \text { European System for Cardiac } \\
& \text { Operative Risk Evaluation }\end{aligned}$} \\
\hline $\mathrm{HR}$ & $=$ hazard ratio \\
\hline IR & $=$ incomplete revascularization \\
\hline LAD & $=$ left anterior descending \\
\hline $\mathrm{LCx}$ & $=$ left anterior circumflex \\
\hline MACCE & $\begin{aligned}= & \text { major adverse cardiac and } \\
& \text { cerebrovascular event }\end{aligned}$ \\
\hline MDCT & $\begin{aligned}= & \text { multidetector computed } \\
& \text { tomography }\end{aligned}$ \\
\hline MI & $=$ myocardial infarction \\
\hline OPCAB & $=$ off-pump coronary artery bypass \\
\hline PCI & $\begin{aligned} &= \text { percutaneous coronary } \\
& \text { intervention }\end{aligned}$ \\
\hline RCA & $=$ right coronary artery \\
\hline
\end{tabular}

\section{METHODS \\ Study Design}

This was a database study using Kokura Memorial Hospital (Fukuoka, Japan) patient medical records. The primary objective of this study was to compare the midterm results between the CR and the IR groups. The secondary objective was to investigate the effect of angiographic patency on midterm events. The study was approved by the Kokura Memorial Hospital Institutional Review Board.

\section{Patients}

From January 2000 to December 2005 inclusive, 1681 patients underwent isolated coronary artery bypass grafting by a single surgeon (H.O.) at Kokura Memorial Hospital. Seventy-seven patients who received CCAB were excluded, and the remaining 1604 (95\%) consecutive OPCAB patients composed the study cohort. Almost half of the CCAB patients were in a hemodynamically unstable condition, even with an intra-aortic balloon pump; the remaining patients had previous cardiac surgery and required cardiopulmonary bypass for resternotomy and exposure. Six OPCAB procedures were converted to $\mathrm{CCAB}$ because of hemodynamic deterioration, and they were included in the cohort of this study. All data were collected prospectively and entered into the institutional database. The definitions of preoperative data in this study were based on those reported in the European System for Cardiac Operative Risk Evaluation (EuroSCORE). ${ }^{14}$ Extracardiac arteriopathy includes any one or more of the following: claudication, carotid occlusion or greater than $50 \%$ stenosis, or previous or planned intervention on the abdominal aorta, limb arteries, or carotids. ${ }^{14}$

CR was defined according to the "traditional" classification described in the Coronary Artery Surgery Study": revascularization is incomplete, with failure to graft into any system with significant stenosis $(>50 \%)$ or lack of grafting into both the left anterior descending (LAD) and circumflex (LCx) systems for $50 \%$ or greater left main trunk disease.

\section{Surgical Technique}

All OPCAB procedures were performed under general anesthesia. The heart was approached via median sternotomy. Heparin (100 KIU/kg and an additional dose) was administered to achieve and maintain the activated clotting time at more than 250 seconds. The strategies of graft selection and distribution have been described elsewhere. ${ }^{15,16}$ In specific cases, when distal vessels in the LCx or right coronary artery (RCA) systems were poorly visualized on preoperative angiography, and the territories of the vessels were deemed to have less myocardial viability based on the results of echocardiography and/or left ventriculography, we did not plan to place any grafts. These 98 cases were also included in the IR group throughout the study. Endarterectomy was performed if a coronary artery had a long, calcified plaque. Heparin was reversed with a halfreversal dose of protamine sulfate. Oral aspirin $(100 \mathrm{mg})$ was administered from postoperative day 1 and through to and including the follow-up period.

\section{Angiographic Evaluation}

Bypass conduits and native coronary arteries were systematically evaluated in $95 \%$ of patients (1422 patients) by catheter-based angiography ${ }^{16}$ or multidetector computed tomography (MDCT; SOMATOM Sensation 16; Siemens AG, Munich, Germany) before discharge with the patients' written informed consent. The postoperative angiography was performed as a routine evaluation, and is standard of care in Japan. Patients with cerebrovascular disease, renal dysfunction, or respiratory failure were excluded for clinical reasons. Although all the patients underwent angiography within the same hospitalization period as the index OPCAB, the dates of the angiography were not available from our database. The experienced interventional cardiologists or the radiologists reviewed the results of graftgraphy. On catheter-based angiography, the conduit was reviewed in at least 2 orthogonal views and scored on the worst appearance of the proximal anastomosis, body of the conduit, and distal anastomosis, according to the FitzGibbon classification. ${ }^{17}$ On MDCT, volume-rendering images and curved multiplanar reconstruction of the anastomotic sites and conduits were constructed to evaluate and score the patency, according to the same classification. Based on the results of angiography, the cardiologists and/or radiologists judged the suitability and the need for postoperative reintervention.

Of 1521 patients who underwent angiographic evaluation, $225(14.8 \%)$ were identified as having at least 1 suboptimal graft (FitzGibbon B or O) and were included in the occlusion group. The remaining 1296 patients were identified as having all patent grafts (FitzGibbon A) and were included in the patent group.

\section{Follow-up}

Complete follow-up was achieved in $99.5 \%$ of cases (median, 3.2 years; range, 1 month to 6.5 years). The patients were followed up in our outpatient clinic at 1, 6, and 12 months after discharge and at yearly intervals thereafter. The latest information was obtained by telephone call or by the attending surgeons consulting the referring cardiologists. Eight patients were lost to follow-up, and their data were censored at the time of the last contact, at which point they were alive and had not had any cardiac events. Prospectively gathered data on follow-up included death from any cause (including in-hospital mortality), MI, reintervention (surgical or percutaneous coronary intervention $[\mathrm{PCI}]$ ), and stroke, which was defined as a neurological deficit diagnosed by a neurologist and confirmed by computed tomography (CT). Major adverse cardiac and cerebrovascular events (MACCEs) were defined as all-cause mortality, nonfatal MI, repeated revascularization (including in-hospital reintervention), or stroke. If more than one event arose in one patient, only the time to the first event was analyzed. 


\section{Statistical Analysis}

Continuous data are expressed as means \pm 1 SD or medians (interquartile range), and categorical variables are expressed as numbers (proportions). Categorical data were compared using the $\chi^{2}$ test and the Fisher exact test. Continuous variables were compared by the Student $t$-test or the Mann-Whitney $U$-test, as appropriate. In the analysis of ranked data, the Kruskal-Wallis test was performed. Multivariable logistic regression analysis was performed to explore predictors of IR. Model variables used in the multivariable analyses were selected a priori on the presumption that they were clinically relevant. The model consisted of the following 22 variables: age, sex (female), body surface area (BSA), number of diseased vessels (3-vessel disease or not), left main disease, 1 or more total occluded lesion(s), congestive heart failure, previous MI, left ventricular ejection fraction (LVEF), atrial fibrillation, chronic renal failure (CRF; nonhemodialysis dependent or hemodialysis dependent), hypertension, hypercholesterolemia, diabetes mellitus (diet or oral drug use or insulin use), chronic obstructive pulmonary disease (COPD), extracardiac arteriopathy, cerebrovascular accident, previous PCI, previous cardiac surgery, and emergency operation. Odds ratios with $95 \%$ confidence intervals (CIs) were given for the logistic regression model. Survival curves were estimated using the Kaplan-Meier method, and differences were demonstrated by the log-rank test. Risk factors for midterm events were explored using the Cox model. In addition to the covariates used in the logistic regression model, the following 6 factors that were clinically relevant and reported by other investigators as predictors ${ }^{10}$ were included in the analysis: conversion to $\mathrm{CCAB}$, bilateral internal thoracic arteries (BITAs), right gastroepiploic artery, saphenous vein graft, number of anastomoses, and IR.

We also addressed potential confounding variables in the observed relationship between IR and survival through a propensity score analysis to account for the probability of a subject experiencing IR. We estimated propensity scores as predicted probabilities from a logistic regression model with IR as the outcome and the previously discussed covariates as predictors. We then created 10 equal-sized strata based on the quantiles of the propensity scores. The stratified Cox regression and the stratified log-rank test were conducted to evaluate the hazard ratio (HR) for survival, with IR versus CR.

Immediately after angiography, many revascularizations were performed in the occlusion group during the index hospitalization. To account for this, another HR for the periods after discharge was calculated for reintervention, in addition to the primary HR for all the reinterventions after surgery. Both occlusion (vs patent) and the interaction between IR and occlusion were tested with separate regression models.

HRs with $95 \%$ CIs were given for the Cox model. Statistical analyses were performed using SPSS statistics, version 19.0 (IBM, Armonk, NY). All $P$ values quoted are 2 sided, and the significance levels were set to .05 .

\section{RESULTS}

\section{Early Results}

There were 216 patients $(13.5 \%)$ who underwent IR. Table 1 presents the baseline characteristics of the 2 groups. In the IR group, there was more 3 -vessel disease $(82 \%$ vs $67 \% ; P<.001)$, previous MI $(53 \%$ vs $42 \% ; P=.002)$, and emergency operations $(12 \%$ vs $7.4 \% ; P=.030)$. Furthermore, the IR group appeared sicker, in that they had a higher prevalence of CRF $(11 \%$ vs $6.8 \% ; P=.035)$. There were no significant differences between the 2 groups with respect to mean age, sex, BSA, or COPD. The logistic EuroSCORE was higher in the IR group (4.0 vs $3.1 ; P<.001)$.

Operative and postoperative variables are also shown in Table 1 . The CR group more frequently received BITA than the IR group ( $79 \%$ vs $70 \% ; P=.006)$. The $\mathrm{CR}$ group had more anastomoses $(3.8 \pm 1.1$ vs $2.9 \pm 0.9 ; P<.001)$. Of
6 emergency conversions to $\mathrm{CCAB}, 5$ were in the IR group $(2.3 \%$ vs $0.1 \% ; P<.001)$.

On postoperative angiography, overall graft patency (ie, FitzGibbon A or B) was $97.5 \%$ (97.5\% in the CR group and $98.3 \%$ in the IR group; $P=.316$ ). The in-hospital mortality rate was slightly higher in the IR group $(P=.085)$. The distribution and patency rates for each graft in OPCAB surgery have been described in our companion article. ${ }^{16}$

The maximum creatine kinase-myocardial band was higher in the occlusion group than in the patent group (median [interquartile range], 14.8 [9.5-31.8] vs 12.7 [8.422.1]; $P=.005)$. Twenty patients $(8.9 \%)$ in the occlusion group experienced perioperative MI (new Q-wave and creatine kinase-myocardial band, >50 IU/L), whereas 17 patients $(1.3 \%)$ had perioperative MI in the patent group $(P<.0001)$. The rates of low cardiac output and inhospital mortality did not differ between the 2 groups ( $P=.61$ and $P=1.0$, respectively).

Ungrafted coronary systems in the IR group were as follows: LAD in 5 patients, LCx in 61 patients, RCA in 145 patients, and both LCx and RCA in 5 patients. The reasons for IR were the presence of a small-caliber coronary artery in 128 patients $(59 \%)$, a diffuse lesion in 20 patients $(9 \%)$, intramyocardial location in 1 patient $(0.5 \%)$, and infarcted area in 51 patients $(24 \%)$. In 16 cases, no reason was given in the operator's note. Multivariable logistic regression analysis was performed to identify predictors of IR; 1 or more total occluded lesion(s), BSA, 3-vessel disease, emergency operation, diabetes mellitus (diet or oral drug use), and female sex were identified as predictors of IR (Table 2).

\section{Midterm Data}

During the follow-up, 184 patients died: 61 from cardiac causes (23 sudden deaths) and 123 from noncardiac causes. Six patients experienced acute MI, and 29 developed stroke. Ninety-four patients received reintervention procedures: 24 received PCI during the same hospitalization as the index OPCAB, 66 underwent PCI after discharge, and 4 had reoperations ( 1 as an in-hospital redo surgery).

Figure 1, $A$, shows the Kaplan-Meier curves for all-cause mortality. The 5 -year survival rates were $74.9 \% \pm 3.7 \%$ for the IR group and $84.9 \% \pm 1.4 \%$ for the CR group (log-rank test, $P<.001)$. As presented in Figure 1, $B$, there were more deaths from cardiac causes in the IR group than in the CR group $(P=.020)$. The disease-free survival rates for cardiac death after 5 years were $91.5 \% \pm 2.4 \%$ in the IR group and $94.4 \% \pm$ $0.9 \%$ in the $\mathrm{CR}$ group. The event-free survival rate for MACCE was significantly lower in the IR group $(66.0 \% \pm$ $4.1 \%)$ than in the CR group $(75.7 \% \pm 1.6 \% ; P<.001)$ (Figure 1,C). There was no difference in the reinterventionfree survival rate between the 2 groups $(P=.179)$.

Results of the Cox model for all-cause mortality are presented in Table 3. The independent predictors of all-cause mortality were age, CRF (hemodialysis dependent and 
TABLE 1. Perioperative characteristics

\begin{tabular}{|c|c|c|c|}
\hline Variables & $C R(N=1388)$ & IR $(N=216)$ & value \\
\hline Age, $y^{*}$ & $68 \pm 9$ & $68 \pm 9$ & .2 \\
\hline Female sex & $389(28)$ & $52(24)$ & \\
\hline $\mathrm{BSA}, \mathrm{m}^{2} *$ & $1.61 \pm 0.17$ & $1.60 \pm 0.16$ & \\
\hline NYHA class $\geq 3$ & $260(19)$ & $51(24)$ & \\
\hline Unstable angina & $311(22)$ & $49(23)$ & \\
\hline Preoperative IABP & $49(3.5)$ & $10(4.6)$ & .4 \\
\hline Emergency operation & $103(7.4)$ & $26(12)$ & \\
\hline Previous MI & $579(42)$ & $114(53)$ & \\
\hline Recent MI (within 90 d) & $133(9.6)$ & $25(12)$ & \\
\hline $\mathrm{CHF}$ & $176(13)$ & $37(17)$ & .0 \\
\hline LVEF, \%* & $62.0 \pm 11.7$ & $58.8 \pm 14.2$ & $<.00$ \\
\hline $\mathrm{AF}$ & $63(4.5)$ & $10(4.6)$ & .86 \\
\hline \multicolumn{4}{|l|}{ Diseased vessels } \\
\hline 1- Or 2-vessel disease & 459 (33) & $39(18)$ & $<.0$ \\
\hline 3-Vessel disease & $929(67)$ & $177(82)$ & $<.00$ \\
\hline Left main disease & $620(45)$ & $87(40)$ & .2 \\
\hline$\geq 1$ Total occlusion & $465(34)$ & $129(60)$ & $<.00$ \\
\hline No. of significant lesions* & $4.0 \pm 1.7$ & $4.3 \pm 1.4$ & .0 \\
\hline Previous PCI & $604(44)$ & $94(44)$ & 1.0 \\
\hline Previous cardiac surgery & $29(2.1)$ & $5(2.3)$ & .79 \\
\hline \multicolumn{3}{|l|}{ CRF $($ creatinine $>200 \mu \mathrm{mol} / \mathrm{L}$ ) } & \\
\hline Nonhemodialysis dependent & $29(2.1)$ & $5(2.3)$ & \\
\hline Hemodialysis dependent & $66(4.8)$ & $19(8.8)$ & \\
\hline \multicolumn{3}{|l|}{ Diabetes mellitus } & .1 \\
\hline Diet or oral drug use & $476(34.3)$ & $84(38.9)$ & \\
\hline Insulin use & $163(11.7)$ & $30(13.9)$ & \\
\hline Hypertension & $925(67)$ & $157(73)$ & \\
\hline Hypercholesterolemia & $778(56)$ & $110(51)$ & .1 \\
\hline COPD & $36(2.6)$ & $7(3.2)$ & \\
\hline Extracardiac arteriopathy & $297(21)$ & $55(26)$ & .1 \\
\hline CVA & $240(17)$ & $48(22)$ & .0 \\
\hline Logistic EuroSCORE $\dagger$ & $3.1(1.7-5.7)$ & $4.0(2.1-8.2)$ & $<.00$ \\
\hline No. of anastomoses* & $3.8 \pm 1.1$ & $2.9 \pm 0.9$ & $<.0$ \\
\hline \multicolumn{4}{|l|}{ Conduits } \\
\hline LITA & $1337(96)$ & $205(95)$ & .3 \\
\hline RITA & $1121(81)$ & $158(73)$ & .0 \\
\hline BITA & $1096(79)$ & $152(70)$ & .0 \\
\hline GEA & $530(38)$ & 34 (16) & $<.00$ \\
\hline SVG & $618(45)$ & $51(24)$ & $<.0$ \\
\hline Radial artery & $47(3.4)$ & $4(1.9)$ & .2 \\
\hline Conversion to $\mathrm{CCAB}$ & $1(0.1)$ & $5(2.3)$ & $<.00$ \\
\hline \multicolumn{3}{|l|}{$\begin{array}{l}\text { Postoperative angiography } \\
(\mathrm{N}=3914 \text { grafts }) \ddagger, \S\end{array}$} & \\
\hline Fitzgibbon A & $3291 / 3512(94)$ & $375 / 402(93)$ & \\
\hline Fitzgibbon B & $132 / 3512(3.8)$ & $20 / 402(5.0)$ & \\
\hline Fitzgibbon O & $89 / 3512(2.5)$ & $7 / 402(1.7)$ & \\
\hline In-hospital mortality & $9(0.6)$ & $4(1.9)$ & \\
\hline Hospital length of stay, $\mathrm{d} \dagger$ & $14(12-19)$ & $15(12-21)$ & \\
\hline
\end{tabular}

Values are given as number (percentage) unless otherwise indicated. $C R$, Complete revascularization; $I R$, incomplete revascularization; $B S A$, body surface area; $N Y H A$, New York Heart Association; IABP, intra-aortic balloon pump; $M I$, myocardial infarction; $C H F$, congestive heart failure; $L V E F$, left ventricular ejection fraction; $A F$, atrial fibrillation; $P C I$, percutaneous coronary intervention; $C R F$, chronic renal failure; $C O P D$, chronic obstructive pulmonary disease; $C V A$, cerebrovascular accident; EuroSCORE, European System for Cardiac Operative Risk Evaluation; LITA, left internal thoracic artery; RITA, right internal thoracic artery; BITA, bilateral
TABLE 2. Multivariable analysis: predictors of incomplete revascularization

\begin{tabular}{|c|c|c|c|}
\hline Variables & $\begin{array}{l}\text { Odds } \\
\text { Ratio }\end{array}$ & $95 \% \mathrm{CI}$ & $\begin{array}{c}P \\
\text { value }\end{array}$ \\
\hline$\geq 1$ Total occluded lesion(s) & 2.81 & 2.04-3.87 & $<.001$ \\
\hline $\mathrm{BSA}, \mathrm{m}^{2}$ & 0.17 & $0.08-0.37$ & $<.001$ \\
\hline 3-Vessel disease & 1.70 & $1.18-2.44$ & .004 \\
\hline Emergency operation & 1.73 & $1.05-2.41$ & .032 \\
\hline Diabetes mellitus (diet or oral drug use) & 1.42 & $1.02-196$ & .035 \\
\hline Female sex & 1.56 & $1.02-2.41$ & .042 \\
\hline LVEF, \% & 0.99 & $0.98-1.00$ & .110 \\
\hline Hypertension & 1.29 & $0.92-1.81$ & .134 \\
\hline CVA & 1.26 & $0.87-1.84$ & .224 \\
\hline CRF (hemodialysis dependent) & 1.43 & $0.80-2.55$ & .231 \\
\hline $\mathrm{CHF}$ & 0.77 & $0.49-1.20$ & .240 \\
\hline Age & 0.99 & $0.98-1.01$ & .243 \\
\hline Diabetes mellitus (insulin use) & 1.30 & $0.81-2.09$ & .274 \\
\hline Hypercholesterolemia & 0.85 & $0.62-1.17$ & .320 \\
\hline $\mathrm{AF}$ & 1.25 & $0.61-2.54$ & .548 \\
\hline Left main disease & 1.08 & $0.79-1.49$ & .623 \\
\hline Previous cardiac surgery & 1.17 & $0.43-3.19$ & .755 \\
\hline Extracardiac arteriopathy & 1.06 & $0.74-1.52$ & .756 \\
\hline Previous MI & 1.05 & $0.74-1.49$ & .790 \\
\hline Previous PCI & 1.00 & $0.74-1.37$ & .979 \\
\hline CRF (non-hemodialysis dependent) & 1.01 & $0.37-2.76$ & .989 \\
\hline COPD & 1.00 & $0.42-2.40$ & .996 \\
\hline
\end{tabular}

$C I$, Confidence interval; $B S A$, body surface area; $L V E F$, left ventricular ejection fraction; $C V A$, cerebrovascular accident; $C R F$, chronic renal failure; $C H F$, congestive heart failure; $A F$, atrial fibrillation; $M I$, myocardial infarction; $P C I$, percutaneous coronary intervention; $C O P D$, chronic obstructive pulmonary disease.

non-hemodialysis dependent), extracardiac arteriopathy, diabetes mellitus (insulin use), saphenous vein graft, and IR (HR, $1.80 ; 95 \%$ CI, $1.15-2.81 ; P=.010$ ), whereas the number of anastomoses and LVEFs was associated with a significantly better outcome.

In the propensity score analysis, the patients were stratified into 10 subgroups based on the estimated probabilities of IR occurring to interpret accurate differences observed in outcome. Applying the stratified Cox regression analysis, the all-cause mortality was also higher in the IR patients than in the CR patients (HR, 1.75; 95\% CI, 1.10-2.79). Also, by the stratified log-rank test, a significant difference was obtained between the IR and CR patients $(P=.019)$.

Figure 2 shows the Kaplan-Meier curves of the patent and occlusion groups. All-cause mortality did not differ between the groups $(P=.461)$. On the other hand, the event-free survival rates for MACCE and reintervention were significantly lower in the occlusion group than in the patent group (both log-rank $P<.001$ ) (Figure $2, A$ and $B$ ). Immediately after angiography, many revascularizations

internal thoracic arteries; $G E A$, gastroepiploic artery; $S V G$, saphenous vein graft; $C C A B$, conventional coronary artery bypass. *Data are given as mean $\pm \mathrm{SD}$. †Data are given as median (interquartile range). †Overall, 1521 patients underwent postoperative angiography (3914 grafts). §Data are given as number/total (percentage). 

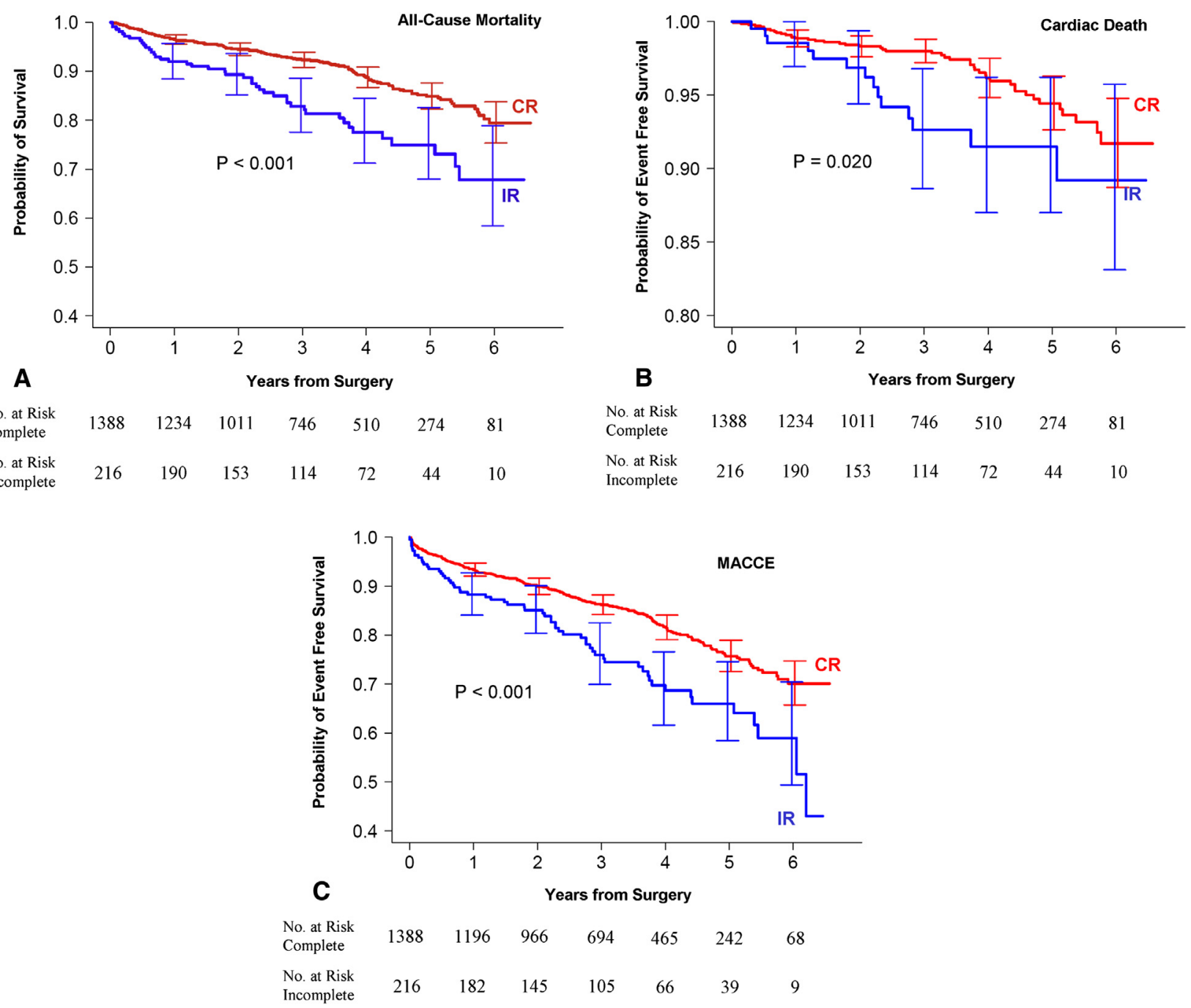

FIGURE 1. Kaplan-Meier estimates for the CR and IR groups. A, Survival curve for all-cause mortality. B, Event-free survival curve for cardiac death. C, Event-free survival curve for MACCE. $C R$, Complete revascularization; $I R$, incomplete revascularization; MACCE, major adverse cardiac and cerebrovascular events.

were performed during index hospitalization (24 PCIs and 1 reoperation). However, when the patients who underwent in-hospital reinterventions were excluded, the event-free survival rate for reintervention was still lower in the occlusion group than in the patent group $(P=.038)$ (Figure 2, $C$ ). The Cox models revealed that graft occlusion was an independent risk factor for both all the reinterventions (HR, 5.49; 95\% CI, 3.44-8.77; $P<.001)$ and the reintervention after discharge (HR, 2.41; 95\% CI, 1.30-4.47; $P=.005$ ). Interaction between IR and graft occlusion was not significant in the regression models for either all-cause mortality or reintervention $(P=.423$ and $P=.511$, respectively).

\section{DISCUSSION}

This study has clearly shown that IR was associated with decreased midterm survival after OPCAB surgery, whereas $\mathrm{CR}$ was not relevant to increased hazard of reintervention.
In contrast, graft occlusion was not associated with overall survival, but was relevant to increased hazard of MACCE or reintervention. IR was also an independent risk factor for all-cause mortality using the Cox model, whereas graft occlusion was an independent risk factor for reintervention. Because the advantage of CR was not limited to groups of patients with low probabilities of IR occurring, there is no evidence of major selection bias, and the results previously stated are not altered by the propensity score analyses.

\section{Completeness of Revascularization}

$\mathrm{CR}$ has been recognized as a surgical mantra since the era of CCAB ${ }^{5,6}$ Alamanni et $\mathrm{al}^{12}$ found that patients with IR experienced perioperative myocardial infarction more frequently than those without IR. Other investigators reported that IR was associated with long-term mortality after $\mathrm{CCAB}^{18}$ and OPCAB. ${ }^{7,8}$ The findings of this study are in 
TABLE 3. Cox hazards analysis for all-cause mortality

\begin{tabular}{|c|c|c|c|}
\hline \multirow[b]{2}{*}{ Variables } & \multicolumn{3}{|c|}{ All-cause mortality } \\
\hline & $\begin{array}{c}\text { Hazard } \\
\text { ratio }\end{array}$ & $95 \%$ CI & $\begin{array}{c}P \\
\text { value }\end{array}$ \\
\hline Age & 1.08 & $1.06-1.10$ & $<.0001$ \\
\hline CRF (hemodialysis dependent) & 4.39 & $2.72-7.06$ & $<.0001$ \\
\hline CRF (non-hemodialysis dependent) & 3.31 & $1.70-6.41$ & $<.0001$ \\
\hline Extracardiac arteriopathy & 1.79 & $1.29-2.49$ & .001 \\
\hline No. of anastomoses & 0.77 & $0.64-0.93$ & .005 \\
\hline LVEF, \% & 0.98 & $0.97-0.99$ & .005 \\
\hline Diabetes mellitus (insulin use) & 1.80 & $1.17-2.77$ & .007 \\
\hline Incomplete revascularization & 1.80 & $1.15-2.81$ & .010 \\
\hline SVG & 1.51 & $1.01-2.24$ & .043 \\
\hline 3-Vessel disease & 0.66 & $0.41-1.06$ & .086 \\
\hline GEA & 1.44 & $0.93-2.20$ & .099 \\
\hline COPD & 1.76 & $0.89-3.48$ & .104 \\
\hline BITA & 1.40 & $0.92-2.12$ & .117 \\
\hline Hypercholesterolemia & 0.79 & $0.58-1.09$ & .149 \\
\hline $\mathrm{CHF}$ & 1.30 & $0.87-1.94$ & .196 \\
\hline CVA & 1.24 & $0.87-1.76$ & .229 \\
\hline Diabetes mellitus (diet or oral drug use) & 1.22 & $0.86-1.71$ & .262 \\
\hline Conversion to $\mathrm{CCAB}$ & 2.19 & $0.51-9.44$ & .292 \\
\hline Previous MI & 0.86 & $0.62-1.21$ & .387 \\
\hline$\geq 1$ Total occluded lesion(s) & 0.86 & $0.61-1.21$ & .397 \\
\hline Previous cardiac surgery & 1.53 & $0.55-4.27$ & .415 \\
\hline Female sex & 1.18 & $0.76-1.85$ & .460 \\
\hline BSA & 0.73 & $0.20-2.64$ & .625 \\
\hline $\mathrm{AF}$ & 1.16 & $0.62-2.18$ & .651 \\
\hline Left main disease & 0.94 & $0.68-1.30$ & .705 \\
\hline Hypertension & 1.05 & $0.74-1.48$ & .789 \\
\hline Emergency operation & 0.95 & $0.57-1.59$ & .850 \\
\hline Previous PCI & 0.98 & $0.72-1.34$ & .883 \\
\hline
\end{tabular}

$C I$, Confidence interval; $C R F$, chronic renal failure; $L V E F$, left ventricular ejection fraction; $S V G$, saphenous vein graft; $G E A$, right gastroepiploic artery; $C O P D$, chronic obstructive pulmonary disease; BITA, bilateral internal thoracic arteries; $C H F$, congestive heart failure; $C V A$, cerebrovascular accident; $C C A B$, conventional coronary artery bypass; $M I$, myocardial infarction; $B S A$, body surface area; $A F$, atrial fibrillation; $P C I$, percutaneous coronary intervention.

line with these previous studies, and the Kaplan-Meier curves diverged over time, although the follow-up was relatively short. On the other hand, 2 investigators reported no difference in survival between CR and IR patients. ${ }^{19,20}$ This discrepancy may be partly the result of the difference in patient selection. Rastan et al ${ }^{19}$ limited the study subjects to patients with left internal thoracic arteryLAD bypasses.

This retrospective study could not identify the reason why IR is associated with midterm survival. However, one possible explanation is that the poorer outcome of the IR group might be ascribed to the differences in patient characteristics. Osswald et $\mathrm{al}^{21}$ noted that advanced coronary artery disease and other comorbidities might account for the higher risk of death after IR. Inasmuch as multivariable logistic regression analysis revealed that the predictors for IR were 1 or more total occluded lesion(s), lower BSA, 3-vessel disease, emergency operation, diabetes mellitus (diet or oral drug use), and female sex (Table 2), IR might serve as a surrogate variable for previous MI. Ischemic cardiomyopathy is well recognized as a predictor of long-term survival after coronary artery bypass grafting. ${ }^{22}$ It is also possible that higher-risk profiles of the IR group account for the decreased survival.

$\mathrm{O}^{\prime}$ Connor et $\mathrm{al}^{23}$ reported that lower BSA and female sex are associated with coronary diameter. Although IR could result from a difficulty of anastomoses in small coronary arteries, myocardial viability may also account for its influence on midterm survival. ${ }^{5}$ In this study, most segments left unbypassed were in the RCA and LCx systems $(98 \%)$. This might partly reflect our grafting strategy. Some of these arteries were left unbypassed because of an occlusion on preoperative angiography. However, they may have been more important than originally recognized. ${ }^{6}$ In addition, patients with poor left ventricular function and predominantly viable myocardium may have a better outcome after revascularization than those with less viability. ${ }^{24}$ However, assessments, such as positron emission tomography, ${ }^{25}$ were not routinely undertaken preoperatively in our series. Outcomes might be expected to improve if the diseased vessels were revascularized in their territories with "hibernating myocardium.,"25

\section{Graft Patency}

Several studies ${ }^{10,11}$ reported that reintervention at follow-up was more frequent among patients undergoing OPCAB than among those undergoing CCAB. Wijeysundera et al, ${ }^{13}$ in their meta-analysis, reported that the mean graft number was 0.19 lower in the OPCAB arm in the randomized studies, and both the randomized and the retrospective studies showed trends toward increased repeated revascularization. The possible causes are IR and the lower patency rate in OPCAB patients. However, the relative contributions of the 2 possible causes have not been determined. ${ }^{10,12,13}$ Lopes et $\mathrm{al}^{9}$ have recently reported that vein graft failure is associated with repeat revascularization after an angiographic follow-up of the Project of Ex Vivo Vein Graft Engineering via Transfection (PRVENT) IV cohort. In our study, similar to their results, the event-free rates for MACCE or reintervention were both significantly lower in the occlusion group $(P<.001$ for both). Twenty-four patients received PCI, and 1 patient underwent a redo operation immediately after graftgraphy (18 PCIs and 1 surgery in the occlusion group), whereas there were 63 PCIs and 3 redo surgeries after discharge. The differences in the event-free rates for MACCE or reintervention between the occlusion and patent groups were mainly due to the early PCI procedures. However, even if in-hospital repeated interventions were excluded, the event-free rate for reintervention was still lower in the occlusion group $(P=.038)$. Achievement of higher patency, in addition to $\mathrm{CR}$, might be expected to lower the rate of adverse cardiac events. It 

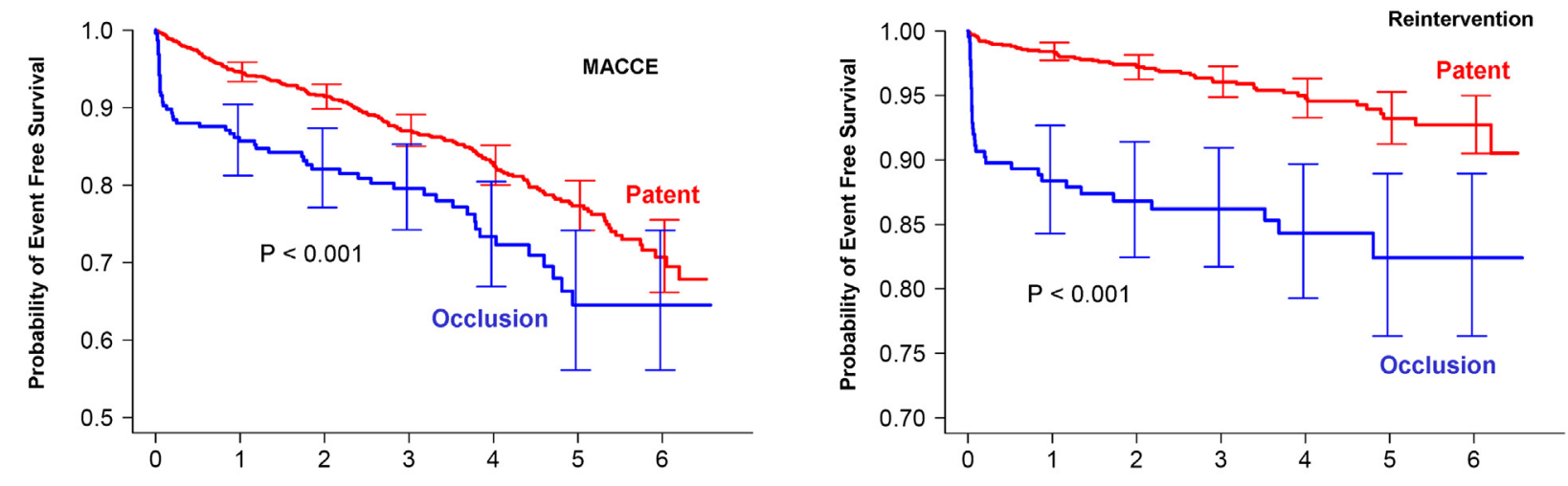

\section{A}

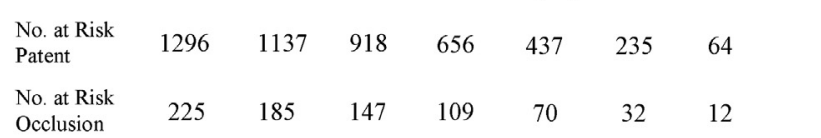

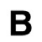

No. at Risk Patent

No. at Risk Occlusion
Years from Surgery $\begin{array}{lllllll}1296 & 1142 & 920 & 668 & 442 & 241 & 65\end{array}$ $\begin{array}{lllllll}225 & 186 & 149 & 111 & 73 & 36 & 13\end{array}$

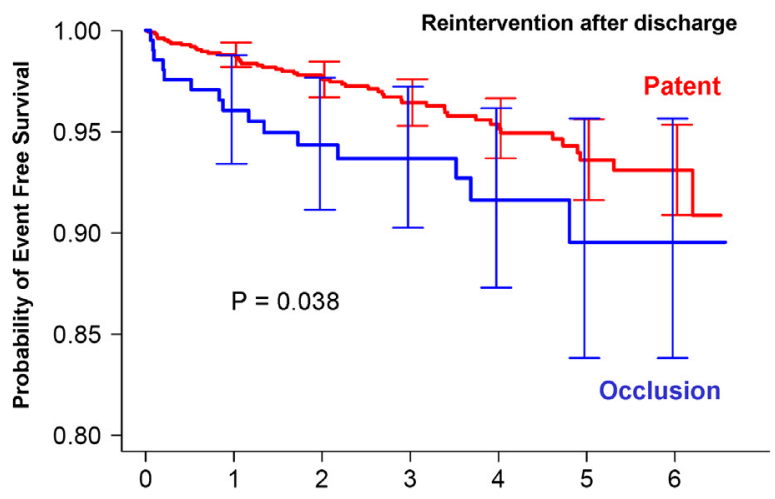

\begin{tabular}{lccccccc}
\multicolumn{1}{c}{ C } & \multicolumn{7}{c}{ Years from Surgery } \\
$\begin{array}{l}\text { No. at Risk } \\
\text { Patent }\end{array}$ & 1291 & 1142 & 920 & 668 & 442 & 241 & 65 \\
$\begin{array}{l}\text { No. at Risk } \\
\begin{array}{l}\text { Occlusion } \\
\text { Non }\end{array}\end{array}$ & 206 & 185 & 148 & 110 & 73 & 36 & 13
\end{tabular}

FIGURE 2. Kaplan-Meier estimates for the patent and occlusion groups. A, Event-free survival curve for MACCE. B, Event-free survival curve for reintervention. C, Event-free survival curve for reintervention after discharge. MACCE, Major adverse cardiac and cerebrovascular event.

is mandatory to explore the optimal graft and target selection in OPCAB surgery. ${ }^{9,16}$

\section{Limitations}

First, because this was a retrospective observational study, confounding biases might not have been eliminated. Multivariable analyses were used in the study to control for differences in prognostic factors. Also, our propensity score analyses did not suggest any substantial selection bias; nevertheless, some unmeasured factors (eg, more complex coronary pathology) were inevitable ${ }^{8}$ and any causal effects cannot be stated. Second, this study was from a single surgeon and a single center, limiting the generalizability of these results. Third, graftgraphy was performed using 2 modalities: catheter-based angiography and multidetector CT. MDCT is generally used in daily practice, but catheter-based coronary angiography remains the gold standard. In addition, the results of those 2 examinations were read by 2 different teams. Although times 0 of the Kaplan-Meier curves for the occlusion and patent groups should be the time of angiographic evaluation, the actual dates of the angiography were not available from our database. Fourth, although interaction between IR and occlusion was not significant, it might be owing to the few patients in the IR and occlusion groups. Fifth, the dominancy of coronary systems or the number of class $\mathrm{C}$ lesions was not noted in our database, and the assessment of infarcted area viability was not routinely performed. Sixth, each patient could not be identified as too small or diffusely diseased, because several patients had more than one reason for incomplete revascularization and some others had no reason given in the operator's note. Finally, because only 
77 patients underwent on-pump CABG in our institution during the study period, we could not compare the angiographic results between OPCAB and on-pump CABG.

\section{CONCLUSIONS}

Incomplete revascularization was relevant to higher midterm mortality after OPCAB, whereas the risks of MACCE and reintervention were higher for patients with occluded grafts. The surgical mantra of CR remains pertinent, even in OPCAB. CR, coupled with achievement of a higher patency rate, could be expected to improve outcomes at follow-up after OPCAB surgery.

\section{References}

1. Nathoe HM, van Dijk D, Jansen EW, Suyker WJ, Diephuis JC, van Boven WJ, et al. A comparison of on-pump and off-pump coronary bypass surgery in lowrisk patients. $N$ Engl J Med. 2003;348:394-402.

2. Shroyer AL, Grover FL, Hattler B, Collins JF, McDonald GO, Kozora E, et al. On-pump versus off-pump coronary-artery bypass surgery. $N$ Engl $\mathrm{J} \mathrm{Med}$. 2009;361:1827-37.

3. Puskas JD, Williams WH, Mahoney EM, Huber PR, Block PC, Duke PG, et al Off-pump vs conventional coronary artery bypass grafting: early and 1-year graft patency, cost, and quality-of-life outcomes: a randomized trial. JAMA. 2004;291: 1841-9.

4. Magee MJ, Coombs LP, Peterson ED, Mack MJ. Patient selection and current practice strategy for off-pump coronary artery bypass surgery. Circulation. 2003;108(suppl 1):III9-14.

5. Bell MR, Gersh BJ, Schaff HV, Holmes DR Jr, Fisher LD, Alderman EL, et al. Effect of completeness of revascularization on long-term outcome of patients with three-vessel disease undergoing coronary artery bypass surgery: a report from the Coronary Artery Surgery Study (CASS) Registry. Circulation. 1992; 86:446-57.

6. Scott R, Blackstone EH, McCarthy PM, Lytle BW, Loop FD, White JA, et al. Isolated bypass grafting of the left internal thoracic artery to the left anterior descending coronary artery: late consequences of incomplete revascularization. J Thorac Cardiovasc Surg. 2000;120:173-84.

7. Cartier R, Bouchot O, El-Hamamsy I. Influence of sex and age on long-term survival in systematic off-pump coronary artery bypass surgery. Eur J Cardiothorac Surg. 2008;34:826-32.

8. Caputo M, Reeves BC, Rajkaruna C, Awair H, Angelini GD. Incomplete revascularization during OPCAB surgery is associated with reduced mid-term eventfree survival. Ann Thorac Surg. 2005;80:2141-7.

9. Lopes RD, Mehta RH, Hafley GE, Williams JB, Mack MJ, Peterson ED, et al. Relationship between vein graft failure and subsequent clinical outcomes after coronary artery bypass surgery. Circulation. 2012;125:749-56.

10. Hannan EL, Wu C, Smith CR, Higgins RS, Carlson RE, Culliford AT, et al. Offpump versus on-pump coronary artery bypass graft surgery: differences in short-term outcomes and in long-term mortality and need for subsequent revascularization. Circulation. 2007;116:1145-52.
11. Williams ML, Muhlbaier LH, Schroder JN, Hata JA, Peterson ED, Smith PK, et al. Risk-adjusted short- and long-term outcomes for on-pump versus offpump coronary artery bypass surgery. Circulation. 2005;112(9 suppl):I366-70.

12. Alamanni F, Dainese L, Naliato M, Gregu S, Agrifoglio M, Polvani GL, et al. Onand off-pump coronary surgery and perioperative myocardial infarction: an issue between incomplete and extensive revascularization. Eur J Cardiothorac Surg. 2008;34:118-26.

13. Wijeysundera DN, Beattie WS, Djaiani G, Rao V, Borger MA, Karkouti K, et al. Off-pump coronary artery surgery for reducing mortality and morbidity: metaanalysis of randomized and observational studies. J Am Coll Cardiol. 2005;46: $872-82$.

14. Nashef SA, Roques F, Michel P, Gauducheau E, Lemeshow S, Salamon R. European system for cardiac operative risk evaluation (EuroSCORE). Eur J Cardiothorac Surg. 1999;16:9-13.

15. Nakano J, Okabayashi H, Hanyu M, Soga Y, Nomoto T, Arai Y, et al. Risk factors for wound infection after off-pump coronary artery bypass grafting: should bilateral internal thoracic arteries be harvested in patients with diabetes? $J$ Thorac Cardiovasc Surg. 2008;135:540-5.

16. Nakano J, Okabayashi H, Noma H, Sato T, Sakata R. Early angiographic evaluation after off-pump coronary artery bypass grafting. J Thorac Cardiovasc Surg. September 20, 2012 [Epub ahead of print].

17. FitzGibbon GM, Kafka HP, Leach AJ, Keon WJ, Hooper GD, Burton JR. Coronary bypass graft fate and patient outcome: angiographic follow-up of 5,065 grafts related to survival and reoperation in 1,388 patients during 25 years. J Am Coll Cardiol. 1996;28:616-26.

18. Sharony R, Bizekis CS, Kanchuger M, Galloway AC, Saunders PC, Applebaum R, et al. Off-pump coronary artery bypass grafting reduces mortality and stroke in patients with atheromatous aortas: a case control study. Circulation. 2003;108(suppl 1):II15-20.

19. Rastan AJ, Walther T, Falk V, Kempfert J, Merk D, Lehmann S, et al. Does reasonable incomplete surgical revascularization affect early or long-term survival in patients with multivessel coronary artery disease receiving left internal mammary artery bypass to left anterior descending artery? Circulation. 2009;120(11 suppl):S70-7.

20. Vander Salm TJ, Kip KE, Jones RH, Schaff HV, Shemin RJ, Aldea GS, et al. What constitutes optimal surgical revascularization? answers from the Bypass Angioplasty Revascularization Investigation (BARI). J Am Coll Cardiol. 2002; 39:565-72.

21. Osswald BR, Blackstone EH, Tochtermann U, Schweiger P, Thomas G, Vahl CF, et al. Does the completeness of revascularization affect early survival after coronary artery bypass grafting in elderly patients? Eur J Cardiothorac Surg. 2001;20:120-5; discussion 125-6.

22. Shah PJ, Hare DL, Raman JS, Gordon I, Chan RK, Horowitz JD, et al. Survival after myocardial revascularization for ischemic cardiomyopathy: a prospective ten-year follow-up study. J Thorac Cardiovasc Surg. 2003;126:1320-7.

23. O'Connor NJ, Morton JR, Birkmeyer JD, Olmstead EM, O'Connor GT. Northern New England Cardiovascular Disease Study Group. Effect of coronary artery diameter in patients undergoing coronary bypass surgery. Circulation. 1996;93:652-5.

24. Pagley PR, Beller GA, Watson DD, Gimple LW, Ragosta M. Improved outcome after coronary bypass surgery in patients with ischemic cardiomyopathy and residual myocardial viability. Circulation. 1997;96:793-800.

25. Shivalkar B, Maes A, Borgers M, Ausma J, Scheys I, Nuyts J, et al. Only hibernating myocardium invariably shows early recovery after coronary revascularization. Circulation. 1996;94:308-15. 